\title{
U7 snRNP is recruited to histone pre-mRNA in a FLASH- dependent manner by two separate regions of the stem-loop binding protein
}

\author{
ALEKSANDRA SKRAJNA, ${ }^{1,2}$ XIAO-CUI YANG, ${ }^{1}$ KATARZYNA BUCHOLC, ${ }^{2}$ JUN ZHANG, ${ }^{3,5}$ \\ TRACI M. TANAKA HALL, ${ }^{3}$ MICHAt DADLEZ, ${ }^{2}$ WILLIAM F. MARZLUFF, ${ }^{1,4}$ and ZBIGNIEW DOMINSKI ${ }^{1,4}$ \\ ${ }^{1}$ Integrative Program for Biological and Genome Sciences, University of North Carolina at Chapel Hill, Chapel Hill, North Carolina 27599, USA \\ ${ }^{2}$ Department of Biophysics, Institute of Biochemistry and Biophysics, Polish Academy of Sciences, 02-106 Warsaw, Poland \\ ${ }^{3}$ Epigenetics and Stem Cell Biology Laboratory, National Institute of Environmental Health Sciences, National Institutes of Health, Research Triangle \\ Park, North Carolina 27709, USA \\ ${ }^{4}$ Department of Biochemistry and Biophysics, University of North Carolina at Chapel Hill, Chapel Hill, North Carolina 27599, USA
}

\begin{abstract}
Cleavage of histone pre-mRNAs at the $3^{\prime}$ end requires stem-loop binding protein (SLBP) and U7 snRNP that consists of U7 snRNA and a unique Sm ring containing two U7-specific proteins: Lsm10 and Lsm11. Lsm11 interacts with FLASH and together they bring a subset of polyadenylation factors to U7 snRNP, including the CPSF73 endonuclease that cleaves histone pre-mRNA. SLBP binds to a conserved stem-loop structure upstream of the cleavage site and acts by promoting an interaction between the U7 snRNP and a sequence element located downstream from the cleavage site. We show that both human and Drosophila SLBPs stabilize U7 snRNP on histone pre-mRNA via two regions that are not directly involved in recognizing the stem-loop structure: helix B of the RNA binding domain and the C-terminal region that follows the RNA binding domain. Stabilization of U7 snRNP binding to histone pre-mRNA by SLBP requires FLASH but not the polyadenylation factors. Thus, FLASH plays two roles in $3^{\prime}$ end processing of histone pre-mRNAs: It interacts with Lsm11 to form a docking platform for the polyadenylation factors, and it cooperates with SLBP to recruit U7 snRNP to histone pre-mRNA.
\end{abstract}

Keywords: histone pre-mRNA; $3^{\prime}$ end processing; SLBP; U7 snRNP; polyadenylation factors; FLASH; Lsm11

\section{INTRODUCTION}

In animal cells, $3^{\prime}$ end cleavage of replication-dependent histone pre-mRNAs depends on U7 snRNP, which functions as an RNA-guided endonuclease (Dominski et al. 2013). U7 snRNP consists of two core components: a 60- to 70-nucleotide (nt) long U7 snRNA and a heptameric Sm ring that contains Lsm 10 and Lsm11 in place of the spliceosomal proteins SmD1 and SmD2 (Schümperli and Pillai 2004). Lsm11 interacts with FLASH (Yang et al. 2009a) and together they recruit to U7 snRNP the histone pre-mRNA cleavage complex (HCC), consisting of multiple polyadenylation subunits, including symplekin, CstF64, CPSF100, and the CPSF73 endonuclease (Sabath et al. 2013; Yang et al. 2013). We refer to this composite particle as holo-U7 snRNP (Fig. 1A). It is unclear whether the holo-U7 snRNP contains all subunits necessary for processing and whether its assembly is regulated

\footnotetext{
${ }^{5}$ Present address: Department of Chemistry, University of Alabama at Birmingham, Birmingham, AL 35294-1240, USA

Corresponding author: dominski@med.unc.edu

Article is online at http://www.rnajournal.org/cgi/doi/10.1261/rna. 060806.117.
}

during the cell cycle, with FLASH binding Lsm11 during the G1/S transition, as suggested by Skrajna et al. (2016).

U7 snRNP is recruited to histone pre-mRNA by the basepairing interaction that involves the $5^{\prime}$ end of the U7 snRNA and the histone downstream element (HDE), a purine-rich variable sequence located in histone pre-mRNAs approximately 15 nt downstream from the cleavage site (Schaufele et al. 1986; Mowry and Steitz 1987; Dominski and Marzluff 2007). In mammalian nuclear extracts, the interaction of U7 snRNP with the HDE is stabilized by the stem-loop binding protein (SLBP), a protein that binds the highly conserved stem-loop structure located upstream of the cleavage site (Wang et al. 1996; Martin et al. 1997). Histone pre-mRNAs that form a strong duplex with U7 snRNA are cleaved in these extracts in the absence of SLBP, although with lower efficiency (Spycher et al. 1994; Dominski and Marzluff 1999). In 


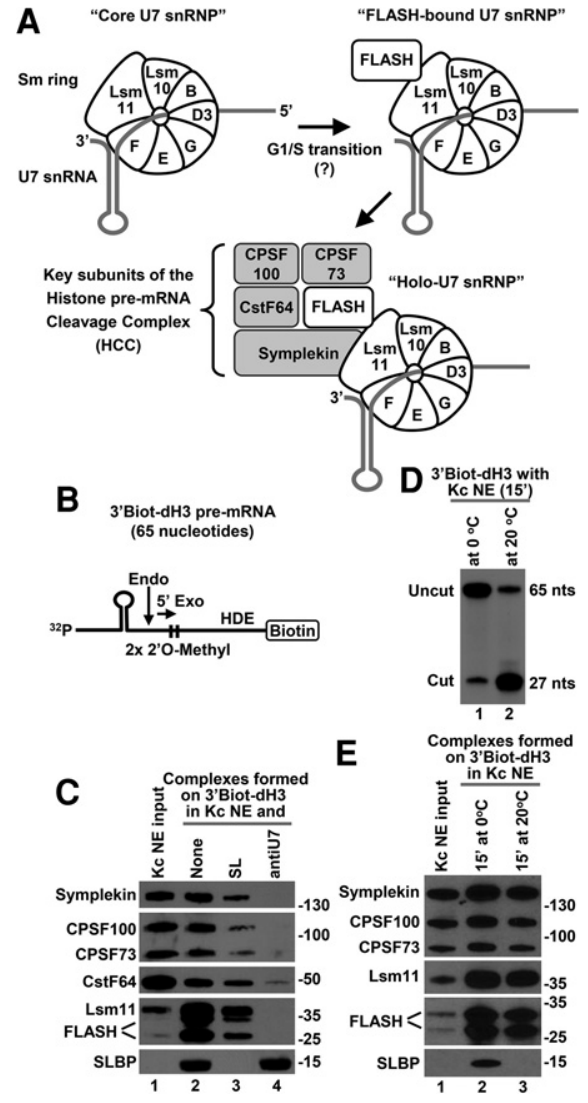

FIGURE 1. Drosophila SLBP promotes the recruitment of U7 snRNP to histone pre-mRNA. (A) Three potential forms of U7 snRNP in nuclear extracts from animal cells. The core U7 snRNP consists of the Sm ring and U7 snRNA. Lsm11 interacts with FLASH to generate the FLASHbound form of U7 snRNP. This step may be cell cycle regulated, occurring during G1/S transition. FLASH and Lsm11 act together to recruit a number of polyadenylation factors, the histone pre-mRNA cleavage complex (HCC), giving rise to the holo-U7 snRNP. Only the key HCC subunits are shown and their arrangement in the complex is arbitrary. (B) Schematic representation of the $3^{\prime}$ Biot-dH3 pre-mRNA used to assemble and purify Drosophila processing complexes. The 65-histone pre-mRNA fragment contains a stem-loop and HDE that bind SLBP and U7 snRNP, respectively (see Materials and Methods for the sequence). Two $2^{\prime} O$-methyl modifications were placed downstream from the cleavage site (Endo) to block potential $5^{\prime}-3^{\prime}$ exonuclease activity of CPSF73 after the cleavage step ( $5^{\prime}$ Exo). A biotin tag is covalently attached to the $3^{\prime}$ end, leaving the $5^{\prime}$ end for labeling with ${ }^{32} \mathrm{P}$, when desired. $(C)$ Proteins bound to $3^{\prime}$ Biot-dH3 pre-mRNA in a Drosophila nuclear extract in the absence (lane 2) or in the presence of indicated competitors (lanes 3,4) were separated in a $4 \%-12 \%$ SDS/polyacrylamide gel and analyzed by Western blotting using antibodies against known processing factors. Lane 1 contains $2.5 \%$ of the input nuclear extract used for formation of the processing complexes. Note that SLBP is limiting in Kc nuclear extracts and undetectable in this amount of the input. Size markers in $\mathrm{kDa}$ are shown to the right. $(D, E) 3^{\prime}$ Biot-dH3 pre-mRNA labeled at the $5^{\prime}$ end was incubated with a Drosophila nuclear extract for $15 \mathrm{~min}$ either on ice or at room temperature to prevent or allow cleavage, respectively. RNA was isolated from a small portion of each reaction and separated in an $8 \%$ denaturing polyacrylamide gel to analyze the extent of cleavage (panel $D$ ). Processing complexes were purified on streptavidin beads from the remaining part of each reaction, separated in a $4 \%-12 \%$ SDS/polyacrylamide gel and analyzed for the presence of selected processing factors by Western blotting (panel $E$ ). Lane 1 in panel $E$ contains $2.5 \%$ of the input nuclear extract. Note that this amount is insufficient to detect SLBP. contrast to mammalian SLBP, Drosophila SLBP is essential for cleavage of all five histone pre-mRNAs in vitro (Dominski et al. 2002b). How Drosophila SLBP functions in processing has not been determined (Sabath et al. 2013).

The structures of human and Drosophila SLBP bound to the stem-loop RNA have been recently resolved by X-ray crystallography (Tan et al. 2013; Zhang et al. 2014). The RNA binding domain (RBD) of each SLBP consists of approximately 70 amino acids and folds into three $\alpha$-helices, with helices $A$ and $\mathrm{C}$ making contacts with the single-stranded region preceding the stem-loop, the $5^{\prime}$ strand of the stem, and individual nucleotides of the loop. Helix B does not participate in RNA recognition and in the structure is located near the disordered C-terminal region that follows the RBD. The disordered C-terminal region in human SLBP consists of 70 residues. The corresponding region of Drosophila SLBP has only 17 amino acids and is highly acidic due to the presence of multiple aspartic acid residues and phosphorylated serines (Dominski et al. 2002b).

Human (Dominski et al. 2001) and Drosophila SLBP (Dominski et al. 2002b) mutated within helix B or the C-terminal region retain the ability to bind the stem-loop structure in histone pre-mRNA but are severely impaired in processing. In this report, to study the role of helix B and the C-terminal region in processing, we assembled mammalian and Drosophila processing complexes in the presence of recombinant SLBP mutants containing various alterations within these two regions. We demonstrate that both helix B and the C-terminal region of Drosophila and human SLBP are essential for the recruitment of U7 snRNP to histone pre-mRNA. We also demonstrate that this function of SLBP depends on FLASH being associated with the core U7 snRNP but not on the polyadenylation subunits of the HCC. Altogether, our results uncover a new role for FLASH in $3^{\prime}$ end processing of histone pre-mRNAs and provide an initial insight into a potential network of protein-protein interactions that bring together SLBP and the U7 snRNP into a stable processing complex, ultimately resulting in high efficiency and fidelity of the cleavage reaction.

\section{RESULTS}

\section{Drosophila SLBP promotes recruitment of U7 snRNP to histone pre-mRNA}

Previously, to purify Drosophila processing complexes on streptavidin agarose beads we used synthetic histone premRNA with biotin at the $5^{\prime}$ end (Sabath et al. 2013). We demonstrated that the amount of holo-U7 snRNP bound to histone pre-mRNA in the presence of SLBP was comparable to the amount bound in the absence of SLBP, suggesting that Drosophila SLBP plays no major role in stabilizing the association of the U7 snRNP with the HDE (Sabath et al. 2013).

In this report, we reinvestigated whether Drosophila SLBP promotes the recruitment of the U7 snRNP to the HDE using 
a new synthetic pre-mRNA, $3^{\prime}$ Biot- $\mathrm{dH} 3$, in which biotin was placed at the $3^{\prime}$ rather than at the $5^{\prime}$ end (Fig. 1B). In $3^{\prime}$ Biot$\mathrm{dH} 3$ pre-mRNA, two nucleotides located between the cleavage site and the HDE were modified with a $2^{\prime} O$ methyl group (Fig. 1B). The $2^{\prime} O$ methyl-modified nucleotides in this position should not affect cleavage of the pre-mRNA but were expected to block subsequent degradation of the downstream cleavage product (DCP) by the $5^{\prime}-3^{\prime}$ exonuclease activity of CPSF73, hence preserving the complex between the U7 snRNP and the HDE (Yang et al. 2009b).

3'Biot-dH3 pre-mRNA was mixed with a Kc nuclear extract and briefly (4-5 min) incubated on ice to initiate formation of processing complexes. The assembled complexes were immobilized on streptavidin beads, extensively washed, and analyzed by Western blotting using antibodies recognizing known processing factors. To determine the role of Drosophila SLBP in the assembly of processing complexes, the Kc nuclear extract was preincubated with an excess of stem-loop RNA (SL), which sequesters endogenous SLBP and prevents its interaction with the pre-mRNA. In a negative control, formation of the processing complexes was blocked by preincubating the extract with an antisense oligonucleotide complementary to the $5^{\prime}$ end of Drosophila U7 snRNA (antiU7) (Sabath et al. 2013).

In the absence of SL RNA and antiU7 oligonucleotide, the 3'Biot-dH3 substrate assembled into processing complexes containing SLBP and the holo-U7 snRNP composed of the core U7 snRNP, as determined by its diagnostic protein Lsm11 (Azzouz and Schümperli 2003; Liu et al. 2006; Nizami et al. 2010), FLASH, and the key subunits of the HCC: CPSF73, CPSF100, symplekin, and CstF64 (Fig. 1C, lane 2). In the presence of SL RNA, no SLBP was bound to histone pre-mRNA, and the amount of U7 snRNP detected in the complex was clearly reduced (Fig. 1C, lane 3). Thus, while Drosophila SLBP is not absolutely essential for the interaction of the U7 snRNP with histone pre-mRNA, it strongly stimulates this interaction. As expected, an antisense oligonucleotide complementary to the $5^{\prime}$ end of the U7 snRNA blocked binding of the U7 snRNP to histone premRNA but did not affect binding of SLBP (Fig. 1C, lane 4). Note that this extract lacks full-length FLASH and SLBP, normally migrating at $\sim 100$ and $40 \mathrm{kDa}$, respectively, and instead contains shorter proteolytic fragments that are fully active in processing (Dominski et al. 2002b; Sabath et al. 2013).

To determine how much of holo-U7 snRNP remains associated with the HDE following cleavage, 3'Biot-dH3 premRNA was labeled with ${ }^{32} \mathrm{P}$ at the $5^{\prime}$ end and incubated for 15 min with Drosophila nuclear extract at $0^{\circ} \mathrm{C}$ or room temperature, to either limit or promote processing. Processing complexes assembled at both temperatures were subsequently purified on streptavidin agarose beads via $3^{\prime}$ biotin. During 15 min incubation on ice, $<10 \%$ of the substrate was cleaved and cleavage increased to $\sim 90 \%$ when incubation was carried out at room temperature (Fig. 1D, lanes 1 and 2, respectively). Processing complexes assembled on ice, in ad- dition to Lsm11, FLASH, and the HCC subunits, contained SLBP, consistent with the majority of pre-mRNA being intact (Fig. 1E, lane 2). In contrast, processing complexes assembled at room temperature contained undetectable amounts of SLBP, consistent with the purification of the $3^{\prime}$ cleavage product. The purified complex contained all the subunits of the U7 snRNP but they were present at reduced levels (Fig. 1E, lane 3). Thus, U7 snRNP becomes partially destabilized on the HDE as a result of cleavage and exclusion of SLBP from the same complex, consistent with the role of SLBP in promoting stable binding of U7 snRNP to its site on histone pre-mRNA. Note that $3^{\prime}$ Biot-dH3 pre-mRNA contains two $2^{\prime} \mathrm{O}$ methyl-modified nucleotides downstream from the cleavage site that prevent degradation of the downstream cleavage product and displacement of the U7 snRNP from the HDE by the $5^{\prime}-3^{\prime}$ exonuclease activity of CPSF73, a post-cleavage step that likely occurs during processing in vivo.

\section{Mutations within helix B and the C-terminal region impair the activity of Drosophila SLBP in processing}

Two regions of Drosophila SLBP may be involved in stabilizing the U7 snRNP on histone pre-mRNA: the highly conserved helix B of the RNA binding domain (RBD) and the variable C-terminal region that contains four aspartic acid residues alternating with four quantitatively phosphorylated serines (Fig. 2A). These two regions do not contact the stem-loop RNA and in the crystal structure are adjacent, suggesting that they might be available for interaction with another processing factor(s) (Zheng et al. 2003; Tan et al. 2013). Moreover, we previously showed that the highly acidic C-terminal region of Drosophila SLBP is essential for processing in Drosophila nuclear extracts (Dominski et al. 2002b).

We generated a number of Drosophila SLBP mutants by altering the sequence of helix B and/or the C terminus (Fig. 2B). In the ER mutant, the AYERY sequence located in helix B (Fig. 2C) was replaced with GYQCY (changed amino acids are underlined). A similar mutation introduced in human SLBP abolished its activity in processing but did not affect RNA binding (Dominski et al. 2001). In the 4 S-4A and 4 S$4 \mathrm{E}$ mutants, the stoichiometrically phosphorylated C-terminal serines (Fig. 2C) were substituted with alanine or glutamic acid residues, respectively, whereas in the h17C mutant the entire C terminus of Drosophila SLBP was replaced by the 17 amino acids found in the corresponding region in human SLBP (Fig. 2B). Finally, we also generated the ER/h17C double mutant where the h17C mutation was combined with the ER mutation. All these mutant proteins were expressed in the baculovirus system, purified and shown by the mobility shift assay to bind the stem-loop RNA (Fig. 2D).

We depleted Drosophila S2 nuclear extract of endogenous SLBP by a specific antibody (Fig. 2E, lane 2) and tested the ability of baculovirus-expressed SLBP variants to restore processing activity in this extract. The SLBP-depleted extract was 


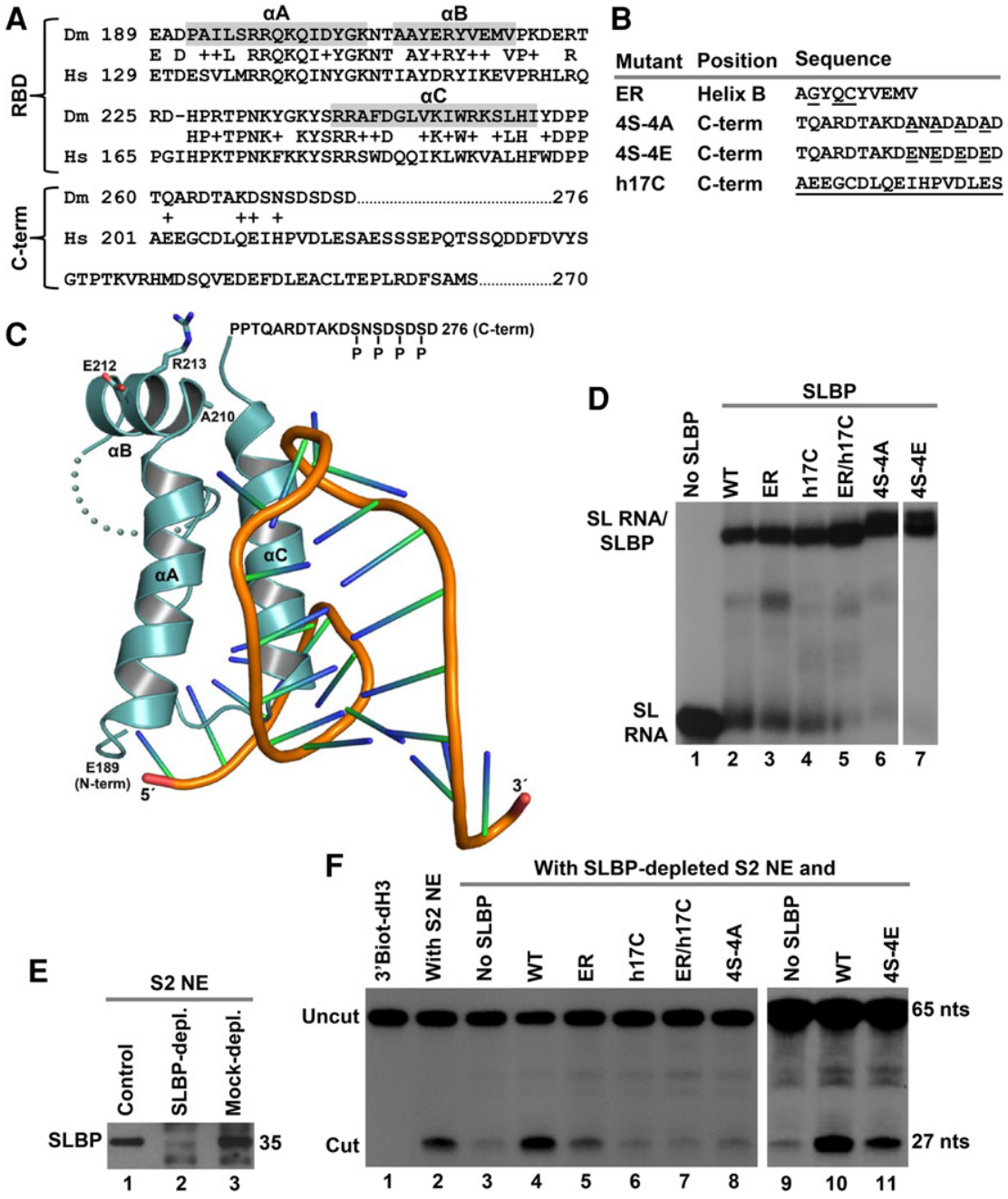

FIGURE 2. Mutations within helix B and the C-terminal region impair the activity of Drosophila $S L B P$ in processing. (A) Protein BLAST alignment of the RNA binding domain (RBD) and the Cterminus of Drosophila (top row) and human SLBP (bottom row). Identical or similar (+) amino acids in the two proteins are shown in the middle row. Note that the C-terminal region of human SLBP is much longer than that in Drosophila SLBP and its end is shown as a separate row the very bottom. The tree $\alpha$-helices of the RBD are highlighted with gray. $(B)$ List of tested SLBP mutants. Changed amino acids are underlined. $(C)$ Ribbon diagram of the RBD of Drosophila SLBP (green) in complex with histone stem-loop RNA (orange) (PDB ID 4TUW). The side chains of the three residues that were mutated in helix $\mathrm{B}$ are shown as stick representations. The sequence of the appended C-terminal tail of SLBP that was disordered in the crystal structure is shown to illustrate its proximity to helix B. The phosphorylated serine residues are indicated. $(D)$ Mobility shift assay to test the ability of mutant SLBPs indicated at the top of each lane to interact with the stem-loop (SL) RNA. The same amount of each protein was incubated with $5^{\prime}$ labeled SL RNA and the complex was analyzed in a native $8 \%$ polyacrylamide gel. SL RNA alone is shown in lane 1. (E) Drosophila S2 nuclear extract was incubated with either an anti-SLBP antibody (lane 2) or a nonspecific antibody (lane 3) and tested by Western blotting for the presence of SLBP using the same anti-SLBP antibody. Untreated Drosophila S2 nuclear extract is shown in lane 1. (F) SLBPdepleted nuclear extract alone (lanes 3,9) or containing indicated recombinant SLBPs (lanes 4$8,10-11$ ) was tested for the ability to cleave $3^{\prime}$ Biot-dH3 pre-mRNA labeled at the $5^{\prime}$ end. Lane 1 contains input $3^{\prime}$ Biot-dH3. Processing in the untreated nuclear extract is shown in lane 2.

only weakly active in cleaving $5^{\prime}$ labeled $3^{\prime}$ Biot- $\mathrm{dH} 3$ premRNA (Fig. 2F, lanes 3,9), and addition of baculovirus-expressed wild type (WT) Drosophila SLBP strongly stimulated processing (Fig. 2F, lanes 4,10). The ER mutant of Drosophila SLBP displayed reduced ability to stimulate processing, (Fig.
2F, lane 5), resembling the behavior of human SLBP mutated in the same region (Dominski et al. 2001). In contrast, the h17C mutation alone or in conjunction with the ER mutation (ER/h17C) abolished the ability of SLBP to complement the depleted extract (Fig. 2F, lanes 6,7), confirming the essential role of the Drosophila C-terminal region in processing.

The 4S-4A mutant SLBP, in which the phosphorylated C-terminal series were replaced by alanines, was unable to complement the SLBP-depleted nuclear extract (Fig. 2F, lane 8). However, the 4S$4 \mathrm{E}$ mutant SLBP, in which the same serines were substituted with glutamic acid residues, was partially active (Fig. 2F, lane 11). Thus, the acidic nature of the C-terminal tail is critical for the activity of Drosophila SLBP in processing, but the negative charge of glutamic acids imperfectly substitutes for the phosphorylated serines.

\section{Helix B and the C-terminal region of Drosophila SLBP are involved in the recruitment of U7 snRNP to histone pre-mRNA}

We analyzed the ability of various SLBP mutants expressed in the baculovirus system to promote binding of U7 snRNP to histone pre-mRNA. Since the removal of SLBP from large amounts of Drosophila nuclear extracts with the anti-SLBP antibody was ineffective, we developed an alternative system for inactivating endogenous SLBP. The $3^{\prime}$ Biot- $\mathrm{dH} 3$ pre-mRNA was first incubated with excess of recombinant Flag-tagged SLBP to assure formation of a quantitative complex, and the complex was next immobilized on streptavidin agarose beads and thoroughly washed. In the second step, the immobilized 3'Biot-dH3 pre-mRNA/SLBP complex was incubated on ice with a Kc nuclear extract containing excess SL RNA to sequester endogenous SLBP (Fig. 3A). The assembled processing complexes were extensively washed and analyzed by Western blotting for the presence of selected processing factors. Binding of each SLBP mutant to histone pre-mRNA was monitored by Western blotting using an antibody directed against the common N-terminal Flag tag. Importantly, 
A

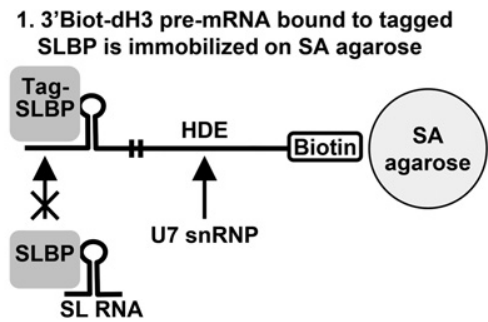

2. SA agarose is incubated with $\mathrm{Kc} \mathrm{NE}+\mathrm{SL}$

3. Processing complexes are purified and analyzed by Western blotting

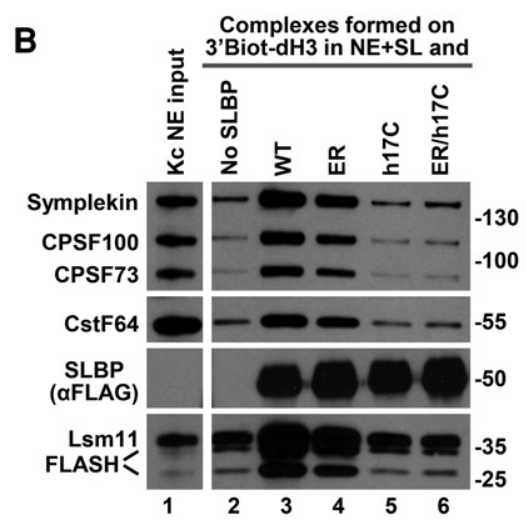

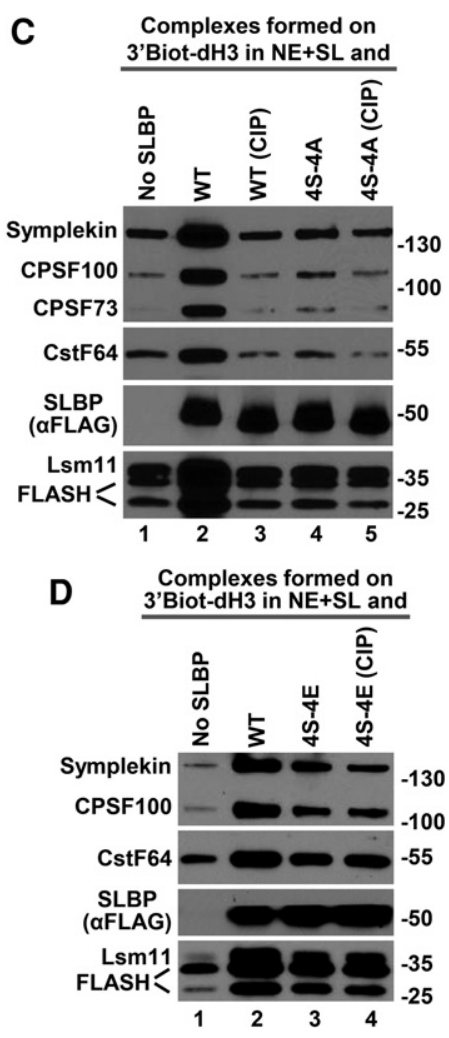

FIGURE 3. The recruitment of U7 snRNP to histone pre-mRNA by Drosophila SLBP. $(A)$ Schematic representation of the experiment to test the activity of recombinant Drosophila SLBPs in stimulating the recruitment of U7 snRNP to $3^{\prime}$ Biot-dH3 histone pre-mRNA in a Drosophila nuclear extract containing stem-loop RNA (SL). Histone pre-mRNA is quantitatively prebound to an excess of recombinant SLBP, and the complex is purified on streptavidin (SA) agarose beads via the $3^{\prime}$ biotin tag (step 1). Drosophila nuclear extract is briefly mixed with excess SL RNA to sequester endogenous SLBP and incubated with SA beads containing $3^{\prime}$ Biot-dH3 premRNA bound to recombinant SLBP (step 2). Complexes immobilized on SA beads are extensively washed and analyzed by Western blotting for the presence of processing factors using specific antibodies (step 3). (B) Processing complexes were formed in the absence of Drosophila SLBP (lane 2) or in the presence of various recombinant SLBPs prebound to histone pre-mRNA, as indicated at the top of lanes 3-6, and analyzed for the presence of selected processing factors by Western blotting. A fraction of the nuclear extract used in the experiment $(2.5 \%)$ is shown in lane 1. Note that this input lane and lane 2 contain no Flag-tagged SLBP. (C) Processing complexes were formed in the presence of prebound WT SLBP (lanes 2,3) or 4S-4A mutant SLBP (lanes 4,5 ), with the proteins being either in a native form (lanes 2,4) or pretreated with calf intestinal phosphatase (CIP) to remove phosphate groups (lanes 3,5). Processing complexes formed in the absence of recombinant SLBP are shown in lane 1. (D) Processing complexes were formed in the presence of prebound WT SLBP (lane 2) or 4S-4E mutant SLBP that was either untreated (lane 3) or pretreated with CIP to remove phosphate groups (lane 4). Processing complexes formed in the absence of recombinant SLBP are shown in lane 1.

SLBP interacts with its RNA target very tightly (Zhang et al. 2014) and as expected, no exchange between recombinant SLBP bound to histone pre-mRNA and endogenous SLBP from the extract bound to SL RNA was observed during the course of the experiment (see below).

Incubation of $3^{\prime}$ Biot-dH3 pre-mRNA alone (no recombinant SLBP) in a nuclear extract containing excess SL RNA resulted in binding of a relatively small amount of the holo-U7 snRNP, as determined by Western blotting of the HCC subunits, FLASH, and Lsm11 (Fig. 3B, lane 2 and Fig. 3C, lane 1). Prebinding of WT Drosophila SLBP to $3^{\prime}$ Biot-dH3
pre-mRNA dramatically increased this amount, demonstrating that the baculovirus expressed Flag-tagged SLBP can substitute for the endogenous protein (Fig. 3B, lane 3 and Fig. 3C, lane 2). The ER SLBP mutant was less active than WT SLBP in recruiting U7 snRNP to histone pre-mRNA (Fig. 3B, lane 4), mirroring the reduced activity of this protein in processing (Fig. 2F, lane 5). Both h17C SLBP and a double mutant that additionally contained the ER mutation were completely inactive in promoting stable binding of the U7 snRNP to histone pre-mRNA (Fig. 3B, cf. lane 2 with lanes 5 and 6), correlating with their null phenotype in processing (Fig. 2F, lanes 6,7). Together, these results suggest that the primary, if not the only, role of helix B and the C-terminal region of Drosophila SLBP in processing is their involvement in stabilizing the interaction between the U7 snRNP and histone pre-mRNA.

We explored the effect of C-terminal phosphorylation on binding of the U7 snRNP to histone pre-mRNA. We used calf intestinal phosphatase (CIP) to remove phosphate groups from WT SLBP, a treatment that makes SLBP inactive in processing (Dominski et al. 2002b). Importantly, the dephosphorylated SLBP failed to promote the interaction of the U7 snRNP with histone premRNA (Fig. 3C, lane 3), providing a plausible explanation for its inability to support processing. Note the change in mobility of WT SLBP as a result of the phosphatase treatment (Fig. 3C, cf. lanes 2 and 3). The 4S-4A SLBP mutant, which lacks four phosphorylation sites in the Cterminal region, displayed barely detectable activity in recruiting U7 snRNP (Fig. 3C, compare signals for CPSF100 and bottom FLASH band in lanes 1 and 4). Interestingly, the same protein following phosphatase treatment was slightly less active (Fig. 3C, cf. lanes 4 and 5), suggesting that at least one other phosphorylated residue in SLBP may contribute to the recruitment of the U7 snRNP. In contrast to 4S-4A SLBP, the $4 \mathrm{~S}-4 \mathrm{E}$ mutant protein, which partially mimics the increased negative charge of phosphorylation, retained significant activity in promoting the recruitment of U7 snRNP to histone pre-mRNA, although it was clearly much weaker than that of the wild-type protein (Fig. 3D, cf. lane 1 with lanes 2 and 3). Thus, glutamic acid residues, while increasing 
the negative charge of the $\mathrm{C}$ terminus, are suboptimal compared to the naturally existing phosphorylated serines. As expected, the partial activity of 4S-4E SLBP in promoting stable interaction of the U7 snRNP to histone pre-mRNA was resistant to CIP treatment (Fig. 3D, lane 4).

Guided by the slight but potentially biologically relevant reduction in the activity of the $4 \mathrm{~S}-4 \mathrm{~A}$ mutant after CIP treatment, we looked for additional phosphorylated residues within the $\mathrm{C}$ terminus of this baculovirus-expressed protein. Mass spectrometry identified a phosphate group at threonine 265 , which is located immediately downstream from aspartic acid residue (position 264) and in close proximity to the SD motifs (Fig. 2A). This phosphorylated DT motif may contribute to the overall negative charge of the C-terminal domain, enhancing the activity of Drosophila SLBP in recruiting U7 snRNP and processing.

\section{FLASH is required for the activity of Drosophila SLBP in recruiting U7 snRNP}

The SLBP-mediated recruitment of the U7 snRNP to histone pre-mRNA likely occurs through a direct or indirect interaction between helix B and the C terminus of Drosophila SLBP and a component/s of the U7 snRNP. To assay for this component, we took advantage of our previous observation that in both mammalian (Yang et al. 2013) and Drosophila nuclear extracts (Sabath et al. 2013), 0.1\% NP40 removes the HCC from the U7 snRNP without affecting the integrity of the core U7 snRNP and its interaction with FLASH. The Biot-dH3 pre-mRNA bound to recombinant WT SLBP was immobilized on streptavidin beads and incubated with a Kc NE containing SL RNA and either no detergent or $0.1 \%$ NP40. In the absence of SLBP, only a basal amount of the U7 snRNP interacted with histone pre-mRNA and WT SLBP strongly stimulated this interaction (Fig. 4A, cf. lanes 1 and 2). Importantly, when processing complexes were assembled in the presence of $0.1 \%$ NP40, the recruitment of Lsm 11 and FLASH to histone pre-mRNA by recombinant WT SLBP was not affected, although the bound U7 snRNP was virtually devoid of symplekin, CPSF100, CPSF73, and CstF64 (Fig. 4A, lane 3). Thus, the activity of SLBP in promoting the recruitment of U7 snRNP to histone pre-mRNA does not depend on the HCC subunits.

To determine whether the SLBP-mediated stabilization of U7 snRNP on histone pre-mRNA depends on FLASH, we treated Drosophila S2 cells with double-stranded RNA (dsFLASH) targeting the FLASH open reading frame (Sabath et al. 2013). The treatment (FLASH-kd) resulted in a significant depletion of full-length FLASH (note that this form was undetectable in the used Kc nuclear extracts) and shorter FLASH forms (Fig. 4B top, cf. lanes 1 and 2) and reduction in the amount of the U7 snRNA (Fig. 3B bottom). The small scale nuclear extract prepared from treated cells was only weakly active in processing (Fig. 4C, lane 3) but importantly, addition of recombinant N-terminal Drosophila
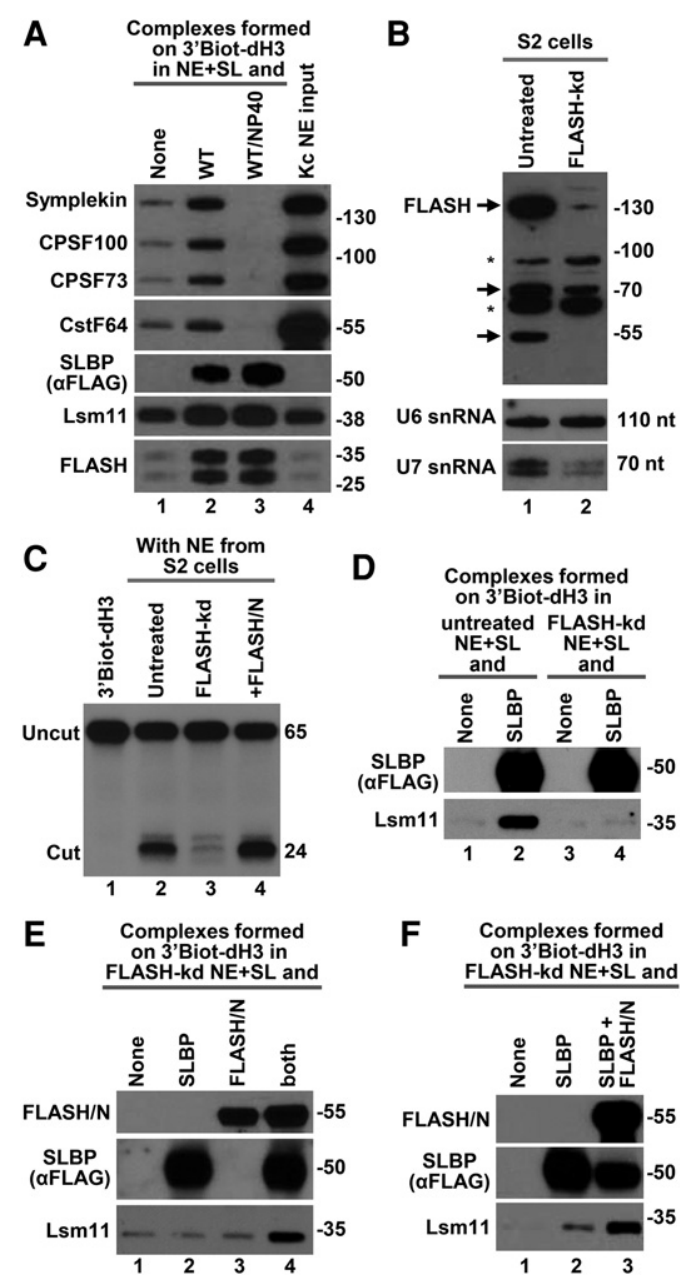

FIGURE 4. FLASH is required for the activity of Drosophila SLBP in recruiting U7 snRNP. (A) Processing complexes were formed on 3'BiotdH3 pre-mRNA prebound to recombinant WT Drosophila SLBP in a Kc nuclear extract containing SL RNA and either no NP40 (lane 2) or $0.1 \%$ NP40 (lane 3). Processing complexes formed in the absence of recombinant SLBP and NP40 are shown in lane 1. Lane 4 contains 5\% of the nuclear extract used in the experiment. Note that this input lane and lane 1 contain no Flag-tagged SLBP. (B) Depletion of FLASH in S2 cells by RNAi. In the top panel, an antibody against the N-terminal FLASH was used to assay the level of endogenous FLASH in untreated S2 cells (lane 1) or FLASH-kd cells treated with double-stranded RNA targeting FLASH ORF (lane 2). Full-length FLASH that migrates close to the 130 $\mathrm{kDa}$ size marker and shorter FLASH forms that are affected by RNAi are indicated with the arrows. Other bands (indicated with asterisks) likely represent proteins that cross-react with the anti-FLASH antibody. In the bottom panel, the same extracts were assayed by Northern blotting for the level of U7 snRNA. U6 snRNA served as a loading control. (C) $3^{\prime}$ end processing of $3^{\prime}$ Biot- $\mathrm{dH} 3$ pre-mRNA was assayed in a nuclear extract from untreated S2 cells (lane 2) or from FLASH-kd cells, either alone (lane 3) or in the presence of recombinant N-terminal FLASH (lane 4). The probe is shown in lane 1. (D) Processing complexes were formed on $3^{\prime}$ Biot-dH3 pre-mRNA in either untreated (lanes 1,2 ) or FLASH-kd (lane 3,4) nuclear extracts containing SL RNA. In lanes 2 and $4,3^{\prime}$ Biot-dH3 pre-mRNA was prebound to WT SLBP. (E,F) Processing complexes were formed on $3^{\prime}$ Biot-dH3 pre-mRNA in FLASH-depleted nuclear extracts in the presence of SL RNA and recombinant proteins indicated at the top of each lane (FLASH/N was added directly to the nuclear extract and WT SLBP was prebound to $3^{\prime}$ Biot$\mathrm{dH} 3$ pre-mRNA). Processing complexes formed in the absence of recombinant proteins are shown in lane 1 (both panels). 
FLASH (FLASH/N, amino acids 1-169) to this extract restored its normal activity (Fig. 4C, lane 4), demonstrating that U7 snRNP was not limiting.

Nuclear extracts prepared from untreated and treated (FLASH-kd) S2 cells were used to assemble processing complexes on $3^{\prime}$ Biot-dH3 pre-mRNA, as depicted in Figure 3A. The stimulatory effect of SLBP was assayed using Lsm11 as a marker of the U7 snRNP. The extract prepared from untreated S2 cells and containing SL RNA to sequester endogenous SLBP behaved in a manner similar to the Kc nuclear extracts, with much larger amounts of U7 snRNP being bound to histone pre-mRNA in the presence than in the absence of prebound recombinant WT SLBP (Fig. 4D, cf. lanes 1 and 2). This stimulatory effect of recombinant SLBP on the recruitment of the U7 snRNP was lost in the FLASH-kd nuclear extract (Fig. 4D, cf. lanes 3 and 4; Fig. 4E, cf. lanes 1 and 2). No effect on the recruitment of the U7 snRNP to histone pre-mRNA was also observed in the presence of only recombinant FLASH/N (Fig. 4E, lane 3). This result was expected since the FLASH-kd nuclear extract contained excess SL RNA to sequester endogenous SLBP. Importantly, prebinding of Flag-SLBP to histone pre-mRNA and addition of recombinant FLASH/N to the FLASH-kd nuclear extract resulted in a clear increase in the amount of the U7 snRNP present in the complex (Fig. 4E, lane 4). Thus, FLASH is an important factor in promoting the recruitment of U7 snRNP to histone pre-mRNA by SLBP.

To confirm this finding, we tested a different batch of FLASH-kd nuclear extract. In this extract, pre-binding of Flag-SLBP to histone pre-mRNA had a noticeable stimulatory effect on the recruitment of the U7 snRNP, likely due to incomplete depletion of endogenous FLASH (Fig. 4F, cf. lanes 1 and 2). However, prebinding of SLBP together with addition of recombinant N-terminal FLASH resulted in a much stronger recruitment of the U7 snRNP to histone pre-mRNA (Fig. 4F, lane 3), consistent with the notion that these two proteins act in conjunction.

\section{Characterization of mouse processing complexes}

Prior to investigating whether the function of the RBD and the C-terminal region in processing is conserved in mammalian SLBP, we carried out a number of experiments to thoroughly characterize mouse processing complexes and assess the stimulatory effect of endogenous SLBP on the recruitment of holo-U7 snRNP to histone pre-mRNA. Endogenous FLASH is limiting and virtually undetectable by Western blotting in mouse nuclear extracts (Yang et al. 2009a, 2011, 2013); and we also tested the effect of the bacterially expressed N-terminal region of human FLASH (FLASH/N, amino acids 1-138) on the composition of the processing complexes. Note that components of human and mouse processing machineries are interchangeable and that all experiments were carried out with nuclear extracts from mouse myeloma cells due to the relatively high concentration of U7 snRNP in these cells.

To assemble mouse processing complexes, we used mouse-specific $5^{\prime}$ Biot-mH $2 \mathrm{a} / 5 \mathrm{~m}$ histone pre-mRNA in which biotin was attached to the $5^{\prime}$ end, and five ribonucleotides around the cleavage site were replaced with $2^{\prime} O$-methyl nucleotides to slow down the cleavage reaction (Yang et al. $2009 \mathrm{~b})$. The pre-mRNA was incubated with a mouse nuclear extract for $5 \mathrm{~min}$ at room temperature and the assembled complexes were immobilized on streptavidin beads, separated in an SDS/polyacrylamide gel and analyzed by Western blotting for the presence of selected components (Fig. 5A, lane 2). Among proteins bound to $5^{\prime}$ Biot- $\mathrm{mH} 2 \mathrm{a} / 5 \mathrm{~m}$ premRNA, we readily identified SLBP and all the key subunits of the HCC: symplekin, CPSF00, CPSF73, and CstF64, indicating that the purified processing complexes contained holo-U7 snRNP. Note that endogenous SLBP, consisting of a number of N-terminally truncated forms (anti-SLBP is directed against the C-terminal peptide), is limiting in the extract and not detectable in the input lane $(2.5 \%)$, but becomes highly enriched in the purified complex. Addition of FLASH/N to the mouse nuclear extract resulted in a clear increase in the amount of the HCC bound to histone premRNA but the level of SLBP remained constant (Fig. 5A, cf. lanes 2 and 4). This effect is consistent with the well-documented role of N-terminal human FLASH in forming the holo-U7 snRNP (Yang et al. 2013). To determine the contribution of SLBP in recruiting U7 snRNP to $5^{\prime}$ Biot-mH2a/5m pre-mRNA, we sequestered endogenous SLBP by adding excess SL RNA to the mouse nuclear extract that either lacked or contained FLASH/N (Fig. 5A, lanes 3,5). The interaction of SLBP with the histone pre-mRNA was prevented in both extracts, as expected, and this effect was accompanied by a drastic reduction of the amount of bound holo-U7 snRNP. Thus, mouse SLBP plays an important role in stabilizing the interaction between U7 snRNP and $5^{\prime}$ Biot-mH2a/5m pre-mRNA. Note that $5^{\prime}$ Biot- $\mathrm{mH} 2 \mathrm{a} / 5 \mathrm{~m}$ pre-mRNA contains an improved HDE that forms 21 base pairs (bp) with the $5^{\prime}$ end of U7 snRNA (Yang et al. 2013). Clearly, this extended duplex is on its own unable to efficiently recruit and/or stably hold the U7 snRNP on histone pre-mRNA.

To get a more direct and unbiased insight into the composition of the mouse processing complexes assembled on 5'Biot-mH2a/5m pre-mRNA, we visualized the bound proteins by silver staining (Fig. 5B, lane 2) and compared them to proteins that were immobilized on streptavidin beads in the absence of histone pre-mRNA (Fig. 5B, lane 1). To identify components of the U7 snRNP, we also prepared a sample that contained the pre-mRNA, but binding of U7 snRNP to the HDE was prevented by addition of an antisense oligonucleotide complementary to the $5^{\prime}$ end of mouse U7 snRNA (antiU7, Fig. 5B, lane 3). All three samples contained recombinant FLASH/N to facilitate the assembly of the holo-U7 snRNP. Several protein bands were detected in the sample containing $5^{\prime}$ Biot-mH2a/5m pre-mRNA but not in the 
A
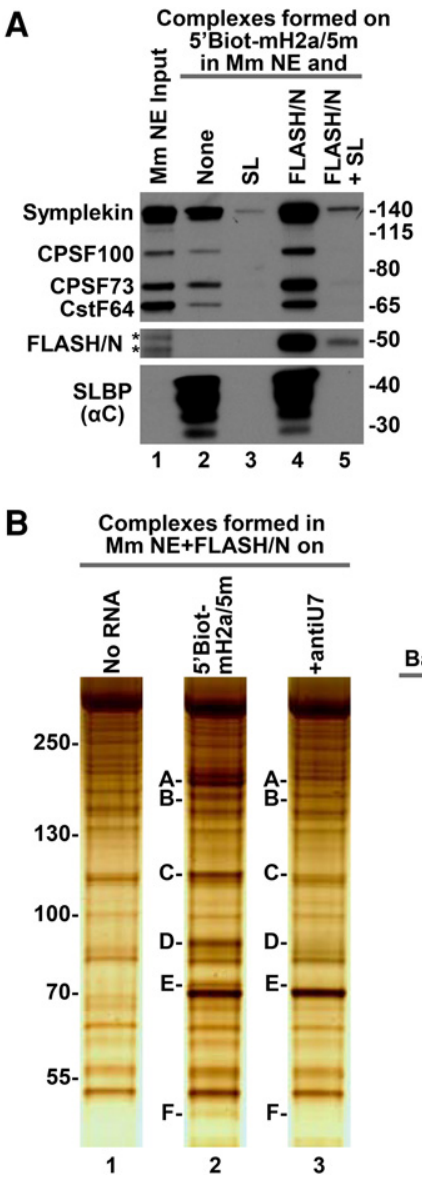

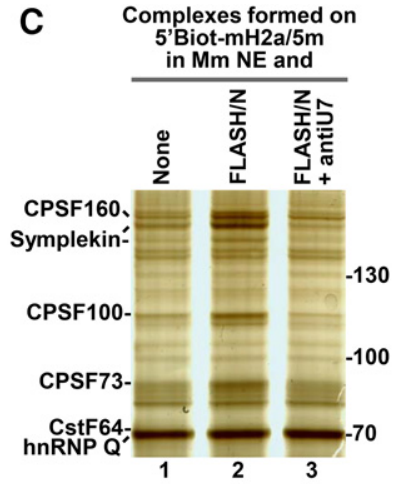

\begin{tabular}{cllrr} 
& & & \multicolumn{2}{c}{ Score } \\
Band & \multicolumn{1}{c}{ ID } & \multicolumn{1}{c}{ Protein } & Lane 2 & Lane 3 \\
\hline A & Q5SWU9 & Acetyl-CoA carboxylase 1 & 630 & 467 \\
& Q9EPU4 & CPSF160 & 451 & 0 \\
Q80X82 & Symplekin & 382 & 0 \\
B Q5SWU9 & Acetyl-CoA carboxylase & 490 & 647 \\
& Q80X82 & Symplekin & 89 & 0 \\
C & O35218 & CPSF100 & 422 & 0 \\
Q5SWU9 & Acetyl-CoA carboxylase 1 & 231 & 432 \\
& Q8VIJ6 & Splicing factor & 220 & 138 \\
D Q9QXK7 & CPSF73 & 348 & 0 \\
Q9D824 & Fip1 & 92 & 0 \\
Q7TMK9 & hnRNP Q & 49 & 59 \\
E Q7TMK9 & hnRNP Q & 500 & 271 \\
Q8BIQ5 & CstF64 & 249 & 0 \\
Q61656 & RNA helicase DDX5 & 182 & 158 \\
F & Q8BUV6 & Lsm11 & 474 & 0 \\
Q5SWU9 & Acetyl-CoA carboxylase 1 & 107 & 78 \\
Q921F2 & TAR DNA-binding protein 43 100 & 31
\end{tabular}

FIGURE 5. Characterization of mouse processing complexes. (A) Processing complexes were formed on $5^{\prime}$ Biot- $\mathrm{mH} 2 \mathrm{a} / 5 \mathrm{~m}$ pre-mRNA in a mouse nuclear extract in the absence or presence of N-terminal human FLASH (FLASH/N, amino acids 1-138) and/or SL RNA, as indicated. The bound proteins were separated in a $4 \%-12 \%$ SDS/polyacrylamide gel and detected by Western blotting. Lane 1 contains $2.5 \%$ of the input nuclear extract that lacks recombinant FLASH. The two bands detected in this lane by the antibody against the N-terminal FLASH (indicated with asterisks) likely represent cross-reactive proteins. Note that SLBP is undetectable in this amount of input. (B) A mouse nuclear extract containing human FLASH/N was used to assemble processing complexes on $5^{\prime}$ Biot- $\mathrm{mH} 2 \mathrm{a} / 5 \mathrm{~m}$ pre-mRNA either in the absence (lane 2 ) or in the presence (lane 3 ) of antiU7 oligonucleotide that blocks the $5^{\prime}$ end of U7 snRNA. In lane 1 , the pre-mRNA was omitted. Proteins purified on streptavidin beads were separated in a $4 \%-12 \%$ SDS/polyacrylamide gel and visualized with silver (left). Small sections (bands $A-F$ ) were excised from the same areas of lanes 2 and 3 and analyzed by mass spectrometry to identify their proteome $($ right $)$. Proteins with the top three scores in each band, with the exception of band B where only two proteins were identified, are listed in the table. $(C)$ Processing complexes were formed on $5^{\prime}$ Biot-mH2a/5m pre-mRNA in a mouse nuclear extract either lacking (lane 1 ) or containing human FLASH/N (lanes 2,3). In lane 3, binding of U7 snRNP to $5^{\prime}$ Biot- $\mathrm{mH} 2 \mathrm{a} / 5 \mathrm{~m}$ pre-mRNA was prevented by an antiU7 oligonucleotide. Proteins purified on streptavidin beads were separated in a $4 \%-12 \%$ SDS/polyacrylamide gel and visualized by silver staining.

sample lacking the pre-mRNA (Fig. 5B, lanes 2 and 1, respectively). Mass spectrometry determined that these bands contained Lsm 11 and known components of the HCC: CPSF160, symplekin (two forms), CPSF100, CPSF73, Fip1, and CstF64 (Fig. 5B, right). The most intensely stained band, migrating at $70 \mathrm{kDa}$ just below CstF64 (band E), was identified as hnRNP Q. Binding of Lsm11 and the HCC subunits to histone premRNA was abolished by the antiU7 oligonucleotide, consistent with these proteins being part of the U7 snRNP. In con- trast, the interaction of hnRNP Q was largely unaffected (Fig. 5B, right). hnRNP Q is an abundant RNA binding protein that likely interacts with the excess of $5^{\prime}$ Biot-mH $2 \mathrm{a} / 5 \mathrm{~m}$ pre-mRNA used in the experiment and has no role in processing, as previously suggested (Yang et al. 2009c). We conclude that among proteins with a molecular weight larger than $45-50 \mathrm{kDa}, \mathrm{Lsm} 11$ and the HCC subunits are the only readily detectable components of the U7 snRNP. Note that the lower portion of the gel containing smaller proteins, including recombinant FLASH/N, SLBP, and Lsm10, stained poorly with silver and is not shown.

Finally, we used silver staining to directly visualize changes that occur in the composition and quantity of processing complexes upon addition of FLASH/ $\mathrm{N}$ to the mouse nuclear extract. In agreement with the results shown in Figure $5 \mathrm{~A}$, the intensity of silver stained bands corresponding to CPSF160, symplekin, CPSF100, and CPSF73 clearly increased in the presence of FLASH/N (Fig. 5C, cf. lanes 1 and 2). In contrast, the amount of hnRNP Q, which is not part of the U7 snRNP, remained constant. As expected, the antiU7 oligonucleotide prevented the interaction of all the polyadenylation factors with $5^{\prime}$ Biot-mH2a/5m pre-mRNA but had no effect on the interaction of hnRNP Q (Fig. 5C, lane 3).

Based on the above results we conclude that $5^{\prime}$ Biot-mH $2 \mathrm{a} / 5 \mathrm{~m}$ is a suitable substrate for the assembly of mouse processing complexes and that the recruitment of U7 snRNP to this histone premRNA is strongly stimulated by SLBP bound to the upstream stem-loop structure. In addition, our results clearly demonstrate that FLASH is limiting in the mouse nuclear extracts and addition of recombinant human FLASH/N increases the amount of the HCC subunits bound to the pre-mRNA.

\section{Regions of human SLBP involved in the recruitment of U7 snRNP to histone pre-mRNA}

To determine whether parts of the RBD and the C-terminal region of human SLBP are involved in the recruitment of U7 snRNP to $5^{\prime}$ Biot-mH2a/5m pre-mRNA, we took advantage of two previously created human SLBP mutants: 9aa-R and 
20aa-C (Dominski et al. 2001, 2002a). In 9aa-R (Fig. 6A), nine amino acids of the RBD that are not essential for binding RNA were replaced by residues found in the same position of Xenopus SLBP2, an oocyte-specific SLBP that is inactive in processing (Ingledue et al. 2000). The substitutions included the highly conserved DR motif and two additional amino acids of helix $\mathrm{B}$, as well as five variable amino acids in the loop that connects helix B with helix C. In 20aa-C SLBP, the 20amino acid region that immediately follows the RBD in human SLBP was substituted with the corresponding but unrelated sequence of Xenopus SLBP2 (Fig. 6A). These two mutants retain the ability to bind SL RNA but are inactive in processing (Dominski et al. 2001, 2002a).

We tested 9aa-R and 20aa-C mutant SLBPs for their ability to promote the recruitment of mouse U7 snRNP to $5^{\prime}$ Biot$\mathrm{mH} 2 \mathrm{a} / 5 \mathrm{~m}$ pre-mRNA using the same approach that we successfully applied to study the function of Drosophila SLBP (Fig. 3A). The experiments were carried out in a mouse nuclear extract that contained recombinant FLASH/N to stimulate the assembly of the holo-U7 snRNP. Excess SL RNA was added to the nuclear extract to sequester endogenous SLBP. In the absence of exogenous SLBP, a relatively small amount of holoU7 snRNP was detected in association with $5^{\prime}$ Biot-mH2a/5m pre-mRNA (Fig. 6B, lane 1), and prebinding of WT human SLBP resulted in a strong increase of this amount (Fig. 6B, cf. lanes 1 and 2). In contrast to WT SLBP, 9aa-R and 20aaC SLBPs prebound to $5^{\prime}$ Biot-mH2a/5m pre-mRNA were only weakly active in promoting formation of a complex containing U7 snRNP (Fig. 6B, lanes 3 and 4), providing a likely explanation for their inability to function in processing.

We previously showed that a chimeric Drosophila SLBP generated by replacing its RBD with the highly similar human RBD was inactive in supporting processing in Drosophila nuclear extracts (Dominski et al. 2002b). The critical ER motif of helix B of Drosophila RBD is conserved in human RBD (DR), suggesting that the observed incompatibility results from differences in other parts of the domain. We now used a reciprocal approach to test whether Drosophila RBD can substitute for the human RBD. In D-H-H SLBP, the N terminus that plays no role in processing was from Drosophila SLBP, and the two remaining domains that are essential for processing, the RBD and the $\mathrm{C}$ terminus, were from human SLBP (Fig. 6A). In D-D-H SLBP, only the Cterminal domain was from human SLBP.

A mouse nuclear extract was depleted of endogenous SLBP by a specific antibody (Fig. 6C, lane 2), resulting in reduced processing of $\mathrm{H} 2 \mathrm{a}-614$ pre-mRNA (Fig. $6 \mathrm{D}$, lane 3). Note that in mammalian nuclear extracts, in contrast to Drosophila nuclear extracts, some processing occurs even in the complete absence of SLBP. The D-H-H chimera was clearly active in enhancing the processing activity of this extract, although it was not as efficient as WT human SLBP (Fig. 6D, cf. lanes 4 and 5). In contrast, the D-D-H chimera whose Drosophila RBD shares $90 \%$ similarity with human $\mathrm{RBD}$, apparently acted in a dominant negative manner to

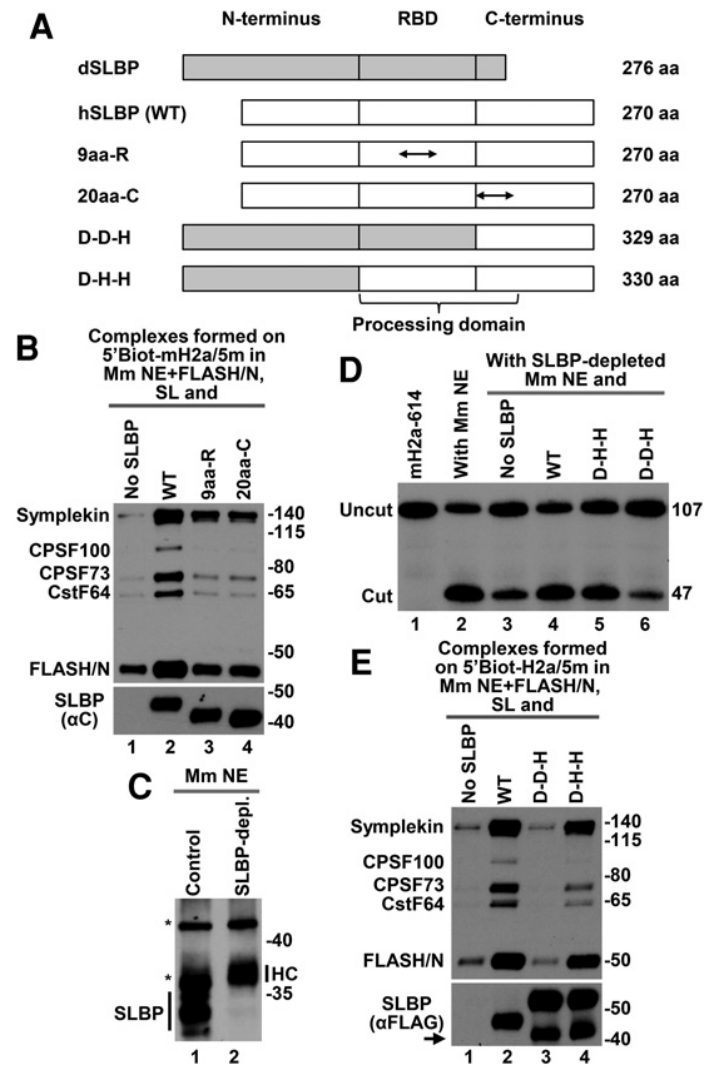

FIGURE 6. Regions of human SLBP required for the recruitment of U7 snRNP to $5^{\prime}$ Biot-mH2a/5m pre-mRNA. (A) Schematic representation of SLBP variants used in the study. The three separate regions in Drosophila SLBP (dSLBP) and human SLBP (hSLBP) are indicated with gray and white boxes, respectively. The activity of each protein in processing depends on the RNA binding domain (RBD) and 15-20 C-terminal amino acids that immediately follow the RBD (processing domain). Doublehead arrows indicate mutated regions in human SLBP. In 9aa-R, the DRYIKEVPRHLRQP sequence in the RBD was replaced with QCYLQEVPKTERKS (changed amino acids are underlined). In 20aa$\mathrm{C}$, the entire C-terminal segment AEEGCDLQEIHPVDLESAES that follows the RBD was replaced with SQNSFQEDHSFKQTQRLLES. (B) Processing complexes were formed on $5^{\prime}$ Biot- $\mathrm{mH} 2 \mathrm{a} / 5 \mathrm{~m}$ pre-mRNA in a mouse nuclear extract containing FLASH/N and SL RNA, as depicted in Figure 3A. The pre-mRNA was used either alone (no recombinant SLBP, lane 1) or prebound to various recombinant SLBPs, as indicated at the top of lanes 2-4. Processing factors bound to $5^{\prime}$ Biot- $\mathrm{H} 2 \mathrm{a} / 5 \mathrm{~m}$ pre-mRNA were detected by Western blotting, using specific antibodies. Note that all recombinant SLBP variants used in the experiment were detected by an antibody directed against the common C-terminal region. (C) Untreated (lane 1) and SLBP-depleted (lane 2) nuclear extracts were analyzed by Western blotting for the presence of SLBP using an anti-SLBP antibody. The asterisks indicate protein bands that cross-react with the anti-SLBP antibody, and HC indicates heavy chain of the residual immunoglobulin in the depleted extract. $(D) 3^{\prime}$ end processing of 5'-labeled mouse $\mathrm{H} 2 \mathrm{a}-614$ pre-mRNA was carried out in an untreated mouse nuclear extract (lane 2), in an SLBP-depleted nuclear extract alone (lane 3), or in the presence of indicated recombinant SLBPs (lanes 4-6). The probe alone is shown in lane 1. (E) Processing complexes were formed on $5^{\prime}$ Biot-mH2a $/ 5 \mathrm{~m}$ pre-mRNA in a mouse nuclear extract containing FLASH/N and SL RNA, as described for panel $B$. All recombinant SLBP variants prebound to $5^{\prime}$ Biot- $\mathrm{mH} 2 \mathrm{a} / 5 \mathrm{~m}$ pre-mRNA contain the Flag tag at the $\mathrm{N}$ terminus and were detected by an antiFlag antibody. Note that $\mathrm{D}-\mathrm{D}-\mathrm{H}$ and $\mathrm{D}-\mathrm{H}-\mathrm{H}$ in addition to full-length protein contain a degradation product (arrow) that likely shortened from the $\mathrm{C}$ terminus. 
further reduce the processing activity of the depleted extract (Fig. 6D, lane 6).

To understand the defect of the $\mathrm{D}-\mathrm{D}-\mathrm{H}$ chimera in processing, we tested its ability to promote the recruitment of the U7 snRNP. While D-H-H displayed clear activity in this assay, although not as robust as that of the WT human SLBP (Fig. 6E, cf. lanes 2 and 4), the D-D-H chimera was inactive and slightly inhibitory (Fig. 6E, cf. lanes 1 and 3), perfectly correlating with the ability of these mutants to support processing. We conclude that the RBD of Drosophila and human SLBP, in spite of their overall strong conservation, including the presence of the $\mathrm{D}(\mathrm{E}) / \mathrm{R}$ motif in helix $\mathrm{B}$, are not functionally interchangeable due to their specificity for U7 snRNP from the same or closely related organism.

\section{Recombinant FLASH stimulates the recruitment of mouse U7 snRNP by SLBP}

We tested whether the ability of mammalian SLBP to promote the recruitment of the U7 snRNP to histone premRNA depends on the HCC. In agreement with the results shown above (Fig. 5A), sequestering of endogenous SLBP in a mouse nuclear extract by excess SL RNA dramatically reduced the interaction $5^{\prime}$ Biot- $\mathrm{mH} 2 \mathrm{a} / 5 \mathrm{~m}$ pre-mRNA with the holo-U7 snRNP (Fig. 7A, cf. lanes 1 and 2). The reduction was clearly visible for all tested components of the holo-U7 snRNP, including FLASH, Lsm11, and the HCC subunits. When the nuclear extract instead of SL RNA contained $0.1 \%$ NP40 to remove the HCC from U7 snRNP, the activity of SLBP in recruiting U7 snRNP, as measured by the level of Lsm11 and FLASH, was unaffected (Fig. 7A, lane 3). Thus, both Drosophila and mammalian SLBP function independently of the HCC.

To investigate whether mammalian SLBP requires FLASH to recruit the U7 snRNP, we took advantage of the limiting level of FLASH in mouse nuclear extracts. Addition of recombinant FLASH/N to a mouse myeloma nuclear extract resulted in an increase of the amount of the HCC subunits bound to $5^{\prime}$ Biot-mH2a/5m pre-mRNA (Fig. 7B, cf. lanes 1 and 2). Importantly, this effect was accompanied by an increase in the amount of Lsm11 and SmB, two proteins of the U7 snRNP Sm ring. Note that the levels of SLBP in the complexes formed in the absence and presence of exogenous FLASH were comparable, indicating that the increase in the amount of the two core U7 proteins is not a result of unequal loading and/or using more pre-mRNA substrate in the extract containing FLASH. We also isolated RNA from a fraction of the complexes containing and lacking recombinant FLASH/ $\mathrm{N}$ and used Northern blotting to compare the amount of U7 snRNA bound to pre-mRNA. The increased level of Lsm11 and SmB observed in the presence of FLASH/N was paralleled by an increase in the amount of U7 snRNA (Fig. 7B, bottom panel, cf. lanes 1 and 2).

We repeated the same experiment using mouse nuclear extract containing $0.1 \%$ NP40 to remove the HCC from U7

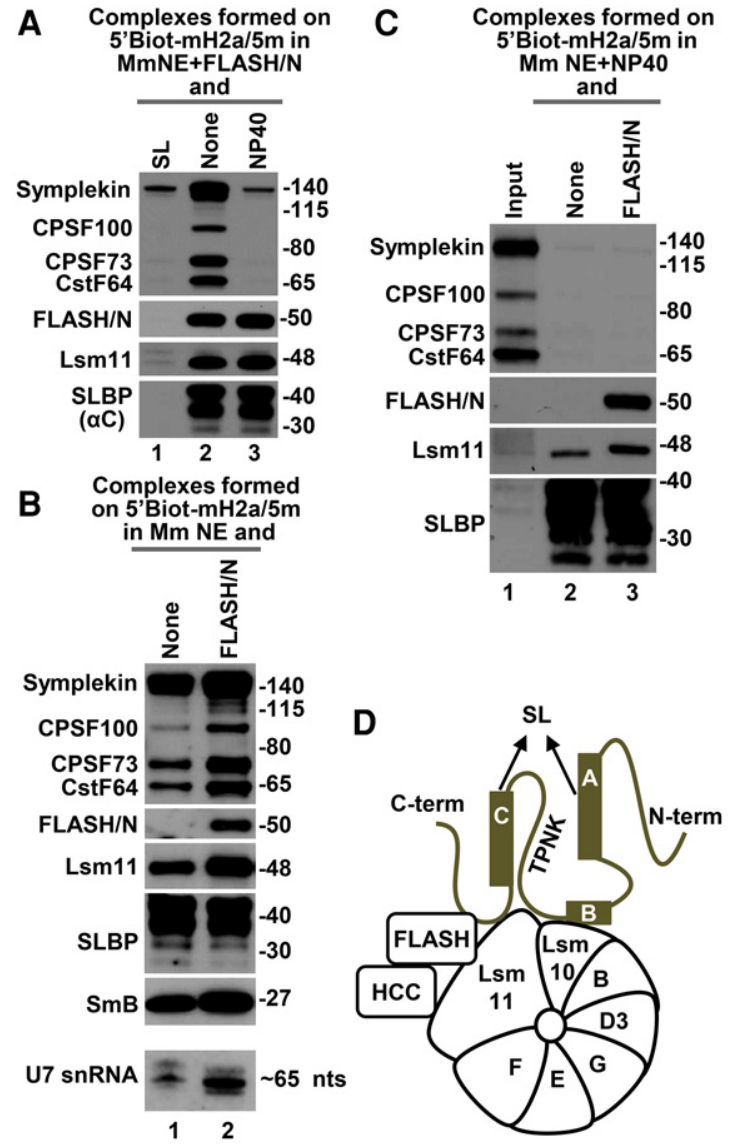

FIGURE 7. Recombinant N-terminal FLASH added to mouse nuclear extracts stimulates the activity of human SLBP in recruiting U7 snRNP. (A) Processing complexes were formed on $5^{\prime}$ Biot-mH2a/5m pre-mRNA in a mouse nuclear extract containing recombinant FLASH/N (lane 2) and compared with processing complexes formed in the same nuclear extract but additionally containing SL to prebind endogenous SLBP (lane 1) or NP40 to remove the HCC from the U7 snRNP (lane 3). (B) Processing complexes were formed on $5^{\prime}$ Biot-mH2a/5m pre-mRNA in a mouse nuclear extract either lacking or containing recombinant FLASH/N. The bound proteins were detected by Western blotting (top panels), and the U7 snRNA was detected by Northern blotting (bottom panel). (C) Processing complexes were formed on 5 'Biot$\mathrm{mH} 2 \mathrm{a} / 5 \mathrm{~m}$ pre-mRNA in a mouse nuclear extract containing $0.1 \%$ NP40 and either lacking (lane 2) or containing recombinant FLASH/N (lane 3 ). Lane 1 contains $2.5 \%$ of the input nuclear extract that lacks recombinant FLASH. Note that Lsm11 and SLBP are only weakly detectable in this amount of input. $(D)$ A hypothetical model that illustrates the potential network of interactions between human SLBP bound to the stem-loop (SL) in histone pre-mRNA and proteins of the U7 snRNP. As demonstrated by structural and biochemical studies, helices $A$ and $C$ recognize RNA, whereas the FLASH/Lsm 11 complex interacts with the HCC. In the model, helix B, part of the loop that connects helices $\mathrm{B}$ and $\mathrm{C}$, and the C-terminal domain interact with FLASH and two specific proteins of the U7 snRNP: Lsm 10 and Lsm11. The depicted interactions are arbitrary and not supported by experimental data.

snRNP. Again, more Lsm 11 bound to $5^{\prime}$ Biot-mH2a/5m pre-mRNA in the presence of recombinant FLASH/N than in its absence (Fig. 7C, cf. lanes 2 and 3). Based on these results, we conclude that the increase in the amount of the HCC bound to histone pre-mRNA observed in the presence 
of recombinant FLASH/N is a result of two independent mechanisms: generation of more holo-U7 snRNP and its more efficient recruitment to the HDE by SLBP (Fig. 7D).

\section{DISCUSSION}

In spite of passing 20 years since the discovery of SLBP as a factor that binds the conserved stem-loop structure in histone pre-mRNA (Wang et al. 1996; Martin et al. 1997), its precise role in processing and interactions with the rest of the processing machinery are incompletely understood. Initial studies in human nuclear extracts demonstrated that human SLBP promotes binding of U7 snRNP to histone pre-mRNA and that the in vitro requirement for SLBP could be bypassed by increasing the extent of complementarity between the $5^{\prime}$ end of the U7 snRNA and the histone downstream element (HDE) (Spycher et al. 1994; Dominski et al. 1999). In contrast, Drosophila SLBP is essential for cleavage of all five Drosophila histone pre-mRNAs in vitro (Dominski et al. 2005), but whether it acts in the same manner as mammalian SLBP and/or has other functions in processing has not been unambiguously determined.

\section{Drosophila SLBP promotes the recruitment of the U7 snRNP to histone pre-mRNA}

Determining the role of Drosophila SLBP in processing proved challenging, in part due to the rapid cleavage of histone pre-mRNAs and hence disruption of the processing complexes containing U7 snRNP during short incubation in Drosophila nuclear extracts. In this report, we used a modified approach for the assembly and purification of Drosophila processing complexes and clearly demonstrate that Drosophila SLBP functionally resembles mammalian SLBP and acts by stabilizing the interaction between the U7 snRNP and histone pre-mRNA. By using a substrate containing biotin at the $3^{\prime}$ end, we show that the U7 snRNP becomes partially destabilized on the HDE after cleavage, when SLBP is no longer part of the complex, further confirming the role of Drosophila SLBP in promoting stable association of U7 snRNP with histone pre-mRNA. Interestingly, the U7 snRNP that remains associated with the HDE following endonucleolytic cleavage contains FLASH and all subunits of the HCC. This result suggests that holo-U7 snRNP does not undergo a major remodeling during the course of processing reaction.

Consistent with our recent studies (Sabath et al. 2013), a detectable amount of Drosophila U7 snRNP binds to histone pre-mRNA in the absence of SLBP, possibly as a result of base-pairing between the $5^{\prime}$ end of the U7 snRNA and the HDE. The bound U7 snRNP contains all the key subunits of the HCC, including the CPSF73 endonuclease, but remains functionally inert. This is in sharp contrast to mammalian holo-U7 snRNP, which when bound to the HDE can result in cleavage of histone pre-mRNA even in the absence of SLBP (Spycher et al. 1994; Dominski et al. 1999). The reason for this difference between the two systems is unknown.

\section{Drosophila and human SLBP use the same regions to recruit U7 snRNP to histone pre-mRNA}

Our results indicate that two regions in mammalian and Drosophila SLBPs are critical for the recruitment of the U7 snRNP to histone pre-mRNA: parts of the RBD that do not directly contact the SL RNA and 15-20 amino acids of the C-terminal region located immediately downstream from the RBD. SLBP mutants altered in these regions retain the ability to bind the SL RNA but are partially or completely impaired in supporting cleavage of histone pre-mRNAs. We show that these mutants are also impaired in recruiting U7 snRNP to histone pre-mRNA, providing a likely molecular basis for their reduced activity in processing.

Within the RBD, the most critical role is played by helix B, including the highly conserved $\mathrm{D}(\mathrm{E}) / \mathrm{R}$ motif. Mutating this motif itself is sufficient to strongly reduce processing activity of human SLBP (Dominski et al. 2001) and the recruitment of U7 snRNP by Drosophila SLBP (this work). An important role in recruiting U7 snRNP may also be played by other amino acids of the RBD, including evolutionarily variable residues in the loop that connects helices B and C. Despite overall conservation, human and Drosophila RBDs are not functionally interchangeable, yielding chimeric proteins that are inactive in both the U7 snRNP recruitment and cleavage of histone pre-mRNAs (Fig. 6D,E; Dominski et al. $2002 \mathrm{~b}$ ). It is possible that these variable amino acids are largely responsible for the observed incompatibility between the two RBDs.

In Drosophila SLBP, the C-terminal region consists of only 17 amino acids and is highly acidic, containing four stoichiometrically phosphorylated serines alternating with four aspartic acids (Dominski et al. 2002b). In addition to these four SD motifs, the C-terminal region contains one TD motif, and our current study indicates that the threonine residue in this motif may be phosphorylated sub-stoichiometrically. The high density of negative charge in this region is critical for the activity of Drosophila SLBP in promoting stable recruitment of the U7 snRNP to histone pre-mRNA and in supporting the cleavage reaction. Interestingly, in the absence of SL RNA the acidic C terminus of Drosophila SLBP associates with helices $\mathrm{A}$ and $\mathrm{C}$, bringing them together and preparing for maximum strength interaction with the SL RNA (Zhang et al. 2014). Upon binding to the RNA target, the phosphorylated C-terminal tail is repelled from the RBD (Zhang et al. 2014) and may become available for the independent function in the recruitment of the U7 snRNP.

The C-terminal region of human SLBP lacks the repeated SD motif present in the Drosophila SLBP. Interestingly, six out of 20 residues that immediately follow the RBD in human SLBP are acidic, suggesting that the overall negative charge of this segment may also be important for activity of this protein 
(Zhang et al. 2014). However, the C-terminal regions of human and Drosophila SLBP are not functionally interchangeable (Dominski et al. 2002b), indicating that they coevolved with other component(s) of their respective processing machineries, resembling the divergent evolution of the two RBDs.

\section{Two functions of FLASH in processing and potential network of interactions spanning the cleavage site}

SLBP tightly bound to the upstream stem-loop promotes stable recruitment of U7 snRNP to histone pre-mRNA likely by directly or indirectly interacting with a subunit(s) of the U7 snRNP. In both Drosophila and mouse nuclear extracts, SLBP is active in recruiting U7 snRNP that lacks the HCC. Thus, SLBP is unlikely to interact with any of the polyadenylation factors of the holo-U7 snRNP. In contrast, removal of FLASH from Drosophila U7 snRNP by RNAi abolishes the ability of SLBP to recruit U7 snRNP to histone pre-mRNA and this ability can be restored by addition of the N-terminal fragment of Drosophila FLASH. Mouse nuclear extracts contain primarily core U7 snRNP (FLASH is limiting), and addition of human N-terminal fragments of human FLASH to a mammalian extract stimulates the activity of SLBP in recruiting the U7 snRNP to histone pre-mRNA.

The N-terminal region of human and Drosophila FLASH was initially characterized as a protein that interacts with Lsm11, hence forming a docking platform for the HCC (Yang et al. 2009a, 2013; Sabath et al. 2013). We now identified a new role for the N-terminal FLASH in processing by showing that it is also essential for the SLBP-mediated "loading" of the U7 snRNP on histone pre-mRNA. This dual FLASH function may be important for the fidelity of $3^{\prime}$ end processing of histone pre-mRNAs in vivo. Clearly, the FLASH-bound U7 snRNP that readily associates with the HCC forming holo-U7 snRNP has an advantage in binding to histone pre-mRNA over functionally incompetent core U7 snRNP, likely preventing misprocessing at downstream cryptic sites by cleavage and polyadenylation.

Previous studies on processing in human cells suggested that the recruitment of U7 snRNP by SLBP might be mediated by ZFP100, a zinc finger protein of $100 \mathrm{kDa}$ that binds both human SLBP (Dominski et al. 2002a) and Lsm11 (Wagner and Marzluff 2006). Our multiple attempts to detect ZFP100 in the mouse processing complexes by silver staining and mass spectrometry failed, although CPSF100 of the same molecular weight was readily identified, arguing against its involvement in the SLBP-mediated recruitment of the U7 snRNP. ZFP100 is a component of histone locus bodies (Wagner and Marzluff 2006) and may play a role in vivo in coupling transcription of histone genes with $3^{\prime}$ end processing of the nascent histone pre-mRNAs.

It is unclear whether SLBP is completely unable to act on the core U7 snRNP and whether its interaction with FLASH is direct or indirect. We favor a model in which SLBP inter- acts with the FLASH/Lsm11 complex rather than with FLASH alone. Alternatively, FLASH, upon binding Lsm11, induces a structural shift in part of Lsm11, making it competent to interact with SLBP. The interaction may also include Lsm10, as envisioned in Figure 7D. Clearly, further studies are required to identify interactions that span across the cleavage site and bring SLBP and U7 snRNP together into a tight processing complex.

\section{Conclusions}

In this study, we developed a method to identify regions in human and Drosophila SLBP that are essential for the recruitment of U7 snRNP to histone-pre-mRNA. In both proteins, this activity is mediated by helix $\mathrm{B}$ and likely other amino acids of the RBD that do not directly contact the SL RNA, and by $\sim 20$ C-terminal amino acids that follow the RBD. We demonstrated that the activity of SLBP in promoting stable recruitment of U7 snRNP to histone pre-mRNA depends on FLASH but not the HCC. Thus, FLASH has two functions in processing: First, it is essential for bringing the HCC to U7 snRNP and second, it cooperates with SLBP in facilitating the interaction between U7 snRNP and histone pre-mRNA. The fact that Drosophila and human SLBP recruit U7 snRNP to histone pre-mRNA through the same regions, and that FLASH but not the HCC is essential for this activity of SLBP, suggests that both processing machineries utilize a conserved network of interactions spanning across the cleavage site.

\section{MATERIALS AND METHODS}

\section{RNAs}

RNA substrates used in this study were synthesized by Dharmacon (GE Healthcare). All sequences are written in the $5^{\prime}-3^{\prime}$ orientation; " $18 \mathrm{~S}$ " and " $\mathrm{m}$ " indicate 18 -atom spacer and $2^{\prime} \mathrm{O}$-methyl group, respectively.

3'Biot-dH3 pre-mRNA, 65-mer, Mol. W. $22 \mathrm{kDa}$, the stem-loop structure is underlined and the cleavage site is indicated with //: UAUAAUCGGUCCUUUUCAGGACCACAA//ACCAGAUUmC mAAUGAGAUAAAAUUUUCUGUUGCCAGCGA-18S-18S-Biot.

Stem-loop (SL) RNA, 31-mer, Mol. W. 9.8 kDa, the stem-loop structure is underlined: GUGCCAAAAAGGCUCUUUUCAGA GCCACCCA.

$5^{\prime}$ Biot-mH2a/5m pre-mRNA, previously referred to as $\mathrm{H} 2 \mathrm{a} / 5 \mathrm{~m}$ (Yang 201318226 /id), 61-mer, Mol. Wt $20.7 \mathrm{kDa}$, the stem-loop structure and the two point mutations in the HDE introduced to improve base-pairing with the U7 snRNA are underlined, the major cleavage site is indicated with //: Biot-18S-18SCUCCCAAAAAGGCUCUUUUCAGAGCCACm $\mathrm{CmCmA} / / \mathrm{mC}$ mUGAAUCAGAUAAAGAGCUGUGACACGGUA.

Mouse-specific anti-U7 oligonucleotide, 15-mer, $5 \mathrm{kDa}, \mathrm{mAm}$ AmGmAmGmCmU mGmUmAmAmCmAmCmU.

Drosophila-specific anti-U7 oligonucleotide, 17-mer, $5.7 \mathrm{kDa}$, mAmGmAmGmAmAmUmAmAmAmAmAmUmUmUmUmC. 


\section{Recombinant proteins}

WT and mutant Drosophila and human SLBPs were expressed in the Bac-to-Bac system (Thermo Fisher Scientific) and purified on nickel beads (Qiagen) via the N-terminal 6×His tag, as recommended by the manufacturer. In all Drosophila SLBPs and in WT human SLBP, the His tag is followed by $3 \times$ Flag tag for detection by Western blotting with an anti-Flag M2 antibody (Sigma-Aldrich). The N-terminal Drosophila FLASH (amino acids 1-169) and human FLASH (amino acids 1-138) were cloned in pET42a vector and expressed in bacteria as fusions with the $\mathrm{N}$-terminal $6 \times \mathrm{His}$ and GST tag, as previously described (Yang et al. 2011, 2013; Sabath et al. 2013). The purity of each recombinant protein was evaluated by electrophoresis in polyacrylamide/SDS gels and Coomassie blue staining.

\section{Antibodies}

The custom-made antibodies used in this study were generated in rabbits against either selected regions or full-length proteins, as described previously (Wang et al. 1996; Yang et al. 2009a; Sabath et al. 2013). Antibodies against Drosophila Lsm10 and Lsm11 (Liu et al. 2006; Nizami et al. 2010) were kindly provided by Joe Gall (Carnegie Institution for Science). Anti-Flag M2 (F3165) and anti-SmB (S0698) mouse monoclonal antibodies were from Sigma.

\section{RNAi}

S2 cells $\left(2 \times 10^{7}\right)$ were initially grown on a six-well plate in a serumfree Sf-900 II medium (Gibco) and treated daily with $10 \mu \mathrm{g}$ of $~ 500$ bp-long double-stranded RNA targeting the FLASH open reading frame (Yang et al. 2009a). After $5 \mathrm{~d}$ of treatment, cells were spun down and used to prepare a small scale nuclear extract (Sabath et al. 2013).

\section{Preparation of nuclear extracts and in vitro processing}

Nuclear extracts from Drosophila Kc and S2 cells and mouse myeloma cells were prepared as previously described (Dominski et al. 1995, 2002b; Sabath et al. 2013). Small-scale in vitro 3' end processing was carried out with $0.5 \mathrm{ng}$ of Drosophila or mammalian-specific pre-mRNA substrates that were labeled at the $5^{\prime}$ end with ${ }^{32} \mathrm{P}$ (Dominski et al. 1995, 2002b). Each reaction in a total volume of $10 \mu \mathrm{L}$ contained $2.5 \mu \mathrm{L}$ of the extract and was incubated at either room temperature (Drosophila nuclear extracts) or $32^{\circ} \mathrm{C}$ (mouse nuclear extracts) for $30 \mathrm{~min}$. When indicated, recombinant $\mathrm{N}$-terminal FLASH was added to the nuclear extract to a final concentration of $25 \mathrm{ng} / \mu \mathrm{L}$. Total RNA was purified by either phenol extraction or treatment with proteinase $\mathrm{K}$ and separated by electrophoresis in an $8 \%$ denaturing polyacrylamide gel. Radioactive RNA species were detected by autoradiography.

\section{Mobility shift assay}

Binding of recombinant SLBPs to the stem-loop RNA was tested using mobility shift assay in native gels, as described previously (Dominski et al. 1995). Of note, 0.5 ng of the stem-loop RNA labeled at the $5^{\prime}$ end with ${ }^{32} \mathrm{P}$ was incubated on ice for $30 \mathrm{~min}$ with $50 \mathrm{ng}$ of recombinant SLBP in $10 \mu \mathrm{L}$ of the processing buffer con- taining $15 \mathrm{mM}$ HEPES-KOH at $\mathrm{pH} 7.9,75 \mathrm{mM} \mathrm{KCl}, 20 \mathrm{mM}$ EDTA, and $15 \%$ glycerol. The resultant complex was resolved from unbound RNA in an $8 \%$ native polyacrylamide gel and the radioactive RNA was detected by autoradiography.

\section{Formation and purification of Drosophila processing complexes}

3'Biot-dH3 pre-mRNA (200 ng) was incubated on ice for $5 \mathrm{~min}$ in a processing reaction (total volume $1 \mathrm{~mL}$ ) containing $750 \mu \mathrm{L}$ of $\mathrm{Kc}$ nuclear extract and $250 \mu \mathrm{L}$ of $80 \mathrm{mM}$ EDTA. When indicated, the nuclear extract contained molar excess of the stem-loop RNA or Drosophila-specific anti-U7 oligonucleotide, each at a final concentration of 5-10 $\mathrm{ng} / \mu \mathrm{L}$. The processing reaction was spun $10 \mathrm{~min}$ in a microcentrifuge at $10 \mathrm{krpm}$, and the supernatant was loaded over 30 $\mu \mathrm{L}$ of streptavidin agarose beads (Sigma) for $1 \mathrm{~h}$ rotation in a cold room. The beads were gently spun down and washed $2 \times 45 \mathrm{~min}$ using a processing mix containing $15 \mathrm{mM}$ HEPES-KOH ( $\mathrm{pH}$ 7.9), 75 $\mathrm{mM} \mathrm{KCl}, 20 \mathrm{mM}$ EDTA, and 15\% glycerol. Proteins immobilized on the beads were eluted in a sample buffer containing $2 \%$ SDS, separated in a $4 \%-12 \%$ gradient SDS/polyacrylamide gel, and detected by Western blotting and/or silver staining.

\section{Formation and purification of mouse processing complexes}

Mouse processing complexes were assembled on $5^{\prime}$ Biot-mH2a/5m pre-mRNA in a mouse nuclear extract following the same protocol that was used for the assembly of Drosophila processing complexes. The only difference was that following the initial 5 min incubation on ice, the sample was shifted to room temperature for an additional 5 min to facilitate complex formation. When indicated, human $\mathrm{N}$ terminal FLASH was added to the nuclear extract to the final concentration of $\sim 25 \mathrm{ng} / \mu \mathrm{L}$. SL RNA and mouse-specific anti-U7 oligonucleotides were added to the final concentration of $5-10 \mathrm{ng} / \mu \mathrm{L}$.

\section{Mapping regions of SLBP involved in the recruitment of U7 snRNP}

The recruitment of Drosophila and mouse U7 snRNP by SLBP was tested using $3^{\prime}$ Biot-dH3 and $5^{\prime}$ Biot-mH2a/5m pre-mRNA, respectively. Each RNA (100 ng) was first incubated on ice with a large excess of recombinant SLBP $(10-50 \mu \mathrm{g})$ in $100 \mu \mathrm{L}$ of the following buffer: $15 \mathrm{mM}$ HEPES-KOH at $\mathrm{pH} 7.9,75 \mathrm{mM} \mathrm{KCl}, 20 \mathrm{mM}$ EDTA, $15 \%$ glycerol, $0.25 \mu \mathrm{g} / \mu \mathrm{L}$ of yeast tRNA, and $0.1 \mu \mathrm{g} / \mu \mathrm{L}$ BSA. After $30 \mathrm{~min}$ incubation, the volume was increased to $1 \mathrm{~mL}$, and the sample was spun $10 \mathrm{~min}$ in a microcentrifuge at $10 \mathrm{krpm}$ to remove any potential protein precipitates. The supernatant was loaded over $\sim 30 \mu \mathrm{L}$ streptavidin agarose beads (Sigma) and rotated for $1 \mathrm{~h}$ in a cold room to bind the SLBP/RNA complex. The beads were extensively washed with the same buffer lacking tRNA and BSA and a small fraction (10\%-15\%) separated on an SDS/polyacrylamide for silver staining and/or Western blotting to determine the amount of bound SLBP. The remaining portion of streptavidin beads was mixed with $400 \mu \mathrm{L}$ of either a mouse nuclear extract (5'Biot-mH2a/5m pre-mRNA) or a Drosophila nuclear extract ( $3^{\prime}$ Biot-dH3 pre-mRNA), each containing $20 \mathrm{mM}$ EDTA and $5 \mu \mathrm{g}$ of SL RNA. Following $60 \mathrm{~min}$ rotation at $4^{\circ} \mathrm{C}$, processing complexes 
immobilized on streptavidin beads were separated from the extract by gently spinning, then were extensively washed and analyzed by Western blotting for the presence of selected processing factors.

\section{ACKNOWLEDGMENTS}

We thank J. Gall (Carnegie Institution for Science) for kindly providing antibodies against Drosophila Lsm10 and Lsm11. We also thank J. Oledzki and A. Fabijanska for mass spectrometry analysis. K.B. and M.D. were supported by the MAESTRO grant from Polish National Science Centre (UMO-2014/14/A/NZ1/00306). This work was funded by the National Institutes of Health grants GM 29832 to W.F.M. and Z.D. and GM 58921 to W.F.M.

Received January 16, 2017; accepted March 9, 2017.

\section{REFERENCES}

Azzouz TN, Schümperli D. 2003. Evolutionary conservation of the U7 small nuclear ribonucleoprotein in Drosophila melanogaster. RNA 9: 1532-1541.

Dominski Z, Marzluff WF. 1999. Formation of the $3^{\prime}$ end of histone mRNA. Gene 239: 1-14.

Dominski Z, Marzluff WF. 2007. Formation of the $3^{\prime}$ end of histone mRNA: getting closer to the end. Gene 396: 373-390.

Dominski Z, Sumerel J, Hanson RJ, Whitfield ML, Marzluff WF. 1995. The polyribosomal protein bound to the $3^{\prime}$ end of histone mRNA can function in histone pre-mRNA processing. RNA 1: 234-236.

Dominski Z, Zheng LX, Sanchez R, Marzluff WF. 1999. Stem-loop binding protein facilitates $3^{\prime}$-end formation by stabilizing U7 snRNP binding to histone pre-mRNA. Mol Cell Biol 19: 3561-3570.

Dominski Z, Erkmann JA, Marzluff WF. 2001. Mutations in the RNA binding domain of stem-loop binding protein define separable requirements for RNA binding and for histone pre-mRNA processing. Mol Cell Biol 21: 2008-2017.

Dominski Z, Erkmann JA, Yang XC, Sànchez R, Marzluff WF. 2002a. A novel zinc finger protein is associated with U7 snRNP and interacts with the stem-loop binding protein in the histone pre-mRNP to stimulate 3'-end processing. Genes Dev 16: 58-71.

Dominski Z, Yang XC, Raska CS, Santiago C, Borchers CH, Duronio RJ, Marzluff WF. 2002b. 3' end processing of Drosophila melanogaster histone pre-mRNAs: requirement for phosphorylated Drosophila stem-loop binding protein and coevolution of the histone premRNA processing system. Mol Cell Biol 22: 6648-6660.

Dominski Z, Yang XC, Purdy M, Marzluff WF. 2005. Differences and similarities between Drosophila and mammalian $3^{\prime}$ end processing of histone pre-mRNAs. RNA 11: 1835-1847.

Dominski Z, Carpousis AJ, Clouet-d'Orval B. 2013. Emergence of the BCASP ribonucleases: highly conserved and ubiquitous metallo-enzymes involved in messenger RNA maturation and degradation. Biochim Biophys Acta 1829: 532-551.

Ingledue TC III, Dominski Z, Sanchez R, Erkmann JA, Marzluff WF. 2000. Dual role for the RNA-binding domain of Xenopus laevis SLBP1 in histone pre-mRNA processing. RNA 6: 1635-1648.

Liu JL, Murphy C, Buszczak M, Clatterbuck S, Goodman R, Gall JG. 2006. The Drosophila melanogaster Cajal body. J Cell Biol 172: 875-884.

Martin F, Schaller A, Eglite S, Schümperli D, Müller B. 1997. The gene for histone RNA hairpin binding protein is located on human chromosome 4 and encodes a novel type of RNA binding protein. EMBO J 16: 769-778.
Mowry KL, Steitz JA. 1987. Both conserved signals on mammalian histone pre-mRNAs associate with small nuclear ribonucleoproteins during $3^{\prime}$ end formation in vitro. Mol Cell Biol 7: 1663-1672.

Nizami Z, Deryusheva S, Gall JG. 2010. The Cajal body and histone locus body. Cold Spring Harb Perspect Biol 2: a000653.

Sabath I, Skrajna A, Yang XC, Dadlez M, Marzluff WF, Dominski Z. 2013. 3'-End processing of histone pre-mRNAs in Drosophila: U7 snRNP is associated with FLASH and polyadenylation factors. RNA 19: 1726-1744.

Schaufele F, Gilmartin GM, Bannwarth W, Birnstiel ML. 1986. Compensatory mutations suggest that base-pairing with a small nuclear RNA is required to form the $3^{\prime}$ end of $\mathrm{H} 3$ messenger RNA. Nature 323: 777-781.

Schümperli D, Pillai RS. 2004. The special Sm core structure of the U7 snRNP: far-reaching significance of a small nuclear ribonucleoprotein. Cell Mol Life Sci 61: 2560-2570.

Skrajna A, Yang XC, Tarnowski K, Fituch K, Marzluff WF, Dominski Z, Dadlez M. 2016. Mapping the interaction network of key proteins involved in histone mRNA generation: a hydrogen/deuterium exchange study. J Mol Biol 428: 1180-1196.

Spycher C, Streit A, Stefanovic B, Albrecht D, Koning TH, Schümperli D. 1994. $3^{\prime}$ end processing of mouse histone premRNA: evidence for additional base-pairing between U7 snRNA and pre-mRNA. Nucleic Acids Res 22: 4023-4030.

Tan D, Marzluff WF, Dominski Z, Tong L. 2013. Structure of histone mRNA stem-loop, human stem-loop binding protein, and $3^{\prime}$ hExo ternary complex. Science 339: 318-321.

Wagner EJ, Marzluff WF. 2006. ZFP100, a component of the active U7 snRNP limiting for histone pre-mRNA processing, is required for entry into S phase. Mol Cell Biol 26: 6702-6712.

Wang ZF, Whitfield ML, Ingledue TC III, Dominski Z, Marzluff WF, 1996. The protein that binds the $3^{\prime}$ end of histone mRNA: a novel RNA-binding protein required for histone pre-mRNA processing. Genes Dev 10: 3028-3040.

Yang XC, Burch BD, Yan Y, Marzluff WF, Dominski Z. 2009a. FLASH, a pro-apoptotic protein involved in activation of C8 is essential for $3^{\prime}$ end processing of histone pre-mRNAs. Mol Cell 36: 267-278.

Yang XC, Sullivan KD, Marzluff WF, Dominski Z. 2009b. Studies of the $5^{\prime}$ exonuclease and endonuclease activities of CPSF-73 in histone pre-mRNA processing. Mol Cell Biol 29: 31-42.

Yang XC, Torres MP, Marzluff WF, Dominski Z. 2009c. Three proteins of the U7-specific Sm ring function as the molecular ruler to determine the site of $3^{\prime}$-end processing in mammalian histone premRNA. Mol Cell Biol 29: 4045-4056.

Yang XC, Xu B, Sabath I, Kunduru L, Burch BD, Marzluff WF, Dominski Z. 2011. FLASH is required for the endonucleolytic cleavage of histone pre-mRNAs but is dispensable for the $5^{\prime}$ exonucleolytic degradation of the downstream cleavage product. Mol Cell Biol 31: 1492-1502.

Yang XC, Sabath I, Debski J, Kaus-Drobek M, Dadlez M, Marzluff WF, Dominski Z. 2013. A complex containing the CPSF73 endonuclease and other polyadenylation factors associates with U7 snRNP and is recruited to histone pre-mRNA for $3^{\prime}$ end processing. Mol Cell Biol 33: 28-37.

Zhang J, Tan D, DeRose EF, Perera L, Dominski Z, Marzluff WF, Tong L, Hall TMT. 2014. Molecular mechanisms for the regulation of histone mRNA stem-loop-binding protein by phosphorylation. Proc Natl Acad Sci 111: E2937-E2946.

Zheng L, Dominski Z, Yang XC, Elms P, Raska CS, Borchers CH, Marzluff WF. 2003. Phosphorylation of stem-loop binding protein (SLBP) on two threonines triggers degradation of SLBP, the sole cell cycle-regulated factor required for regulation of histone mRNA processing, at the end of S phase. Mol Cell Biol 23: 1590-1601. 

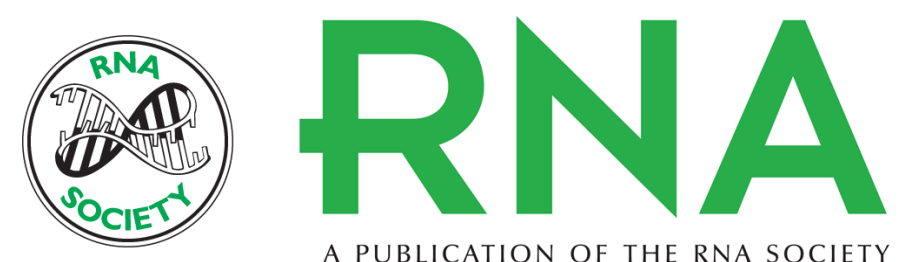

A PUBLICATION OF THE RNA SOCIETY

\section{U7 snRNP is recruited to histone pre-mRNA in a FLASH-dependent manner by two separate regions of the stem-loop binding protein}

Aleksandra Skrajna, Xiao-cui Yang, Katarzyna Bucholc, et al.

RNA 2017 23: 938-951 originally published online March 13, 2017

Access the most recent version at doi:10.1261/rna.060806.117

\section{References This article cites 30 articles, 22 of which can be accessed free at: http://rnajournal.cshlp.org/content/23/6/938.full.html\#ref-list-1 \\ Creative This article is distributed exclusively by the RNA Society for the first 12 months after the Commons full-issue publication date (see http://rnajournal.cshlp.org/site/misc/terms.xhtml). After 12 License months, it is available under a Creative Commons License (Attribution-NonCommercial 4.0 International), as described at http://creativecommons.org/licenses/by-nc/4.0/.}

Email Alerting Receive free email alerts when new articles cite this article - sign up in the box at the Service top right corner of the article or click here.

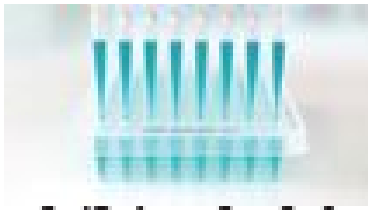

\section{Providing Precise Solutions for} your research.

To subscribe to $R N A$ go to:

http://rnajournal.cshlp.org/subscriptions 